\title{
The recent 10-year landscape of aortic dissection research: a bibliometric analysis
}

\author{
Jinlin $\mathrm{Wu}^{1}$, Rui Zhao ${ }^{2}$, Donglin Zhuang ${ }^{1,3}$, Jiade Zhu ${ }^{1}$, Haiyun Zheng $^{1}$, Jimei Chen ${ }^{1}$ \\ ${ }^{1}$ Department of Cardiac Surgery, Guangdong Cardiovascular Institute, Guangdong Provincial People's Hospital, Guangdong Academy of Medical \\ Sciences, Guangzhou, China; ${ }^{2}$ Department of Vascular Surgery, Fuwai Hospital, National Center for Cardiovascular Diseases, Chinese Academy of \\ Medical Sciences and Peking Union Medical College, Beijing, China; ${ }^{3}$ Shantou University Medical College, Shantou, China \\ Contributions: (I) Conception and design: J Wu; (II) Administrative support: J Wu, J Chen; (III) Provision of study materials or patients: J Wu, \\ R Zhao; (IV) Collection and assembly of data: J Wu, D Zhuang, J Zhu; (V) Data analysis and interpretation: J Wu, R Zhao, H Zheng; (VI) \\ Manuscript writing: All authors; (VII) Final approval of manuscript: All authors. \\ Correspondence to: Jinlin Wu, MD; Jimei Chen, MD. Department of Cardiac Surgery, Guangdong Cardiovascular Institute, Guangdong Provincial \\ People's Hospital, Guangdong Academy of Medical Sciences, Guangzhou, China. Email: wujinlin_fuwai@126.com; 13609777314@163.com.
}

Background: We aimed to comprehensively analyze all the literature related to aortic dissection (AD) in the past decade using Web Scrapping technology from PubMed, revealing the research dynamics in this field.

Methods: Data were retrieved and downloaded from PubMed with search strategy as "(aortic dissection [Title/Abstract]) AND (2010[EDAT]: 2020[EDAT])”. Information on the PMID, journal name, title, number of citations, publication year, authors, affiliations, abstract, study type, and keywords of the research was recorded.

Results: A total of 7,470 publications were identified. Most of the articles were published in 7 Thorac Cardiovasc Surg; Japan was the country with the largest publications number; the USA was far ahead of other countries regarding the highly cited studies; Yale University and Baylor College of Medicine took the first place for publishing most of the highly cited articles; the most frequently cited article is the 2014 ESC Guidelines on the diagnosis and treatment of aortic diseases; most of the clinical trials were published on 7 Vasc Surg; John A. Elefteriades ranked first by cumulative publication numbers; Christoph A. Nienaber took the lead by both cumulative citations and impact factors; Dianna M. Milewicz was the only female researcher on all the three ranking lists; the most common keywords in aortic dissection were Treatment Outcome and Retrospective Studies.

Conclusions: This study provides interesting insights into the AD scientific landscape in recent 10 years and generates some objective evidence for comprehensive understanding and evaluation of this field. This investigation may ultimately inform managers, researchers and policymakers.

Keywords: Aortic dissection; bibliometric; PubMed

Submitted Nov 10, 2020. Accepted for publication Jan 22, 2021.

doi: $10.21037 /$ jtd-20-3272

View this article at: http://dx.doi.org/10.21037/jtd-20-3272

\section{Introduction}

Aortic dissection $(\mathrm{AD})$, the well-known "ticking time bomb" in medicine, was estimated to be 4.4 per 100,000 person- year (1). In view of its urgency and high risk, researchers have always had a strong interest in this disorder, rendering it one of the hotspots in cardiovascular researches. A large number of literature about $\mathrm{AD}$ are published every year. It is 
no exaggeration to say that we are in an era of information explosion, which is of both opportunity and challenge. It's very hard for any researcher in this filed to grasp the "full image" of AD research. Therefore, it is important to sort out and summarize the literature systematically, so that readers can obtain information more efficiently and in a broader view. Traditionally, Review has been the main approach of literature mining and curation, which requires a lot of manual reading and extraction, so it can only be used to summarize and evaluate specific parts of a specialty. To establish a more comprehensive summarization and evaluation, a more efficient and advanced way is necessitated-bibliometrics.

Bibliometrics refers to an interdisciplinary science of quantitative analysis of literature using mathematics and statistics. At present, there are few bibliometric reports in the field of $\mathrm{AD}$. We aimed to comprehensively analyze all the literature related to $\mathrm{AD}$ on PubMed in the past decade using Web Scrapping technology, from different aspects of researchers, journals, institutions, and countries, etc., revealing the research dynamics in this field, and to a certain extent, helping other researchers foresee the research trends.

\section{Methods}

The study was approved by the Chinese Ethics Committee of Registering Clinical Trials (ChiECRCT-20180041), with informed consent waived. Statistical analysis and data visualization were performed using the $\mathrm{R}$ 3.6.1 ( $\mathrm{R}$ Foundation for Statistical Computing, Vienna, Austria).

Data were retrieved and downloaded using RISmed and pubmed.mineR packages from PubMed, a website (http:// www.ncbi.nlm.nih.gov/pubmed/) that provides free access to biomedical journal citations and abstracts. A total of 7,470 publications were identified using the following PubMed search strategy: "(aortic dissection [Title/Abstract]) AND (2010 [EDAT]: 2020 [EDAT])". Of note, the closing date for the current study was July $31^{\text {st }}, 2020$. There were no other restrictions such as study types, abstract availability, language, etc. Information on the PMID, journal name (both full name and abbreviated), title, number of citations, publication year, authors, affiliations, abstract, study type, and keywords of the research was recorded. The full text was downloaded if necessary.

\section{Statistical analysis}

The following $\mathrm{R}$ packages were used for cleaning, analysis, and plotting: rio, stringr, plyr, ggplot2, circlize, ggmap, maps, and ggrepel. Descriptive analyses were conducted to calculate the frequencies of published articles on the level of journals, authors, countries, etc. Association between the journal IF and the number of citations was assessed using the Pearson Correlation test and a two-sided $\mathrm{P}$ value of less than 0.05 was considered significant. Further, Word cloud diagrams were generated to visualize the keywords frequencies. The authors' cooperation network was represented by a chord graph. In addition, we used maps to present geographic information (such as countries and research centers). The top 100 highly cited articles in the past decade were independently screened and evaluated by two researchers (Rui Zhao and Donglin Zhuang). Any discrepancies between the two authors would be discussed in a core meeting to reach an agreement.

\section{Results}

As shown in Figure 1, most of the literature about AD were published in 7 Thorac Cardiovasc Surg (389, 5.2\%), followed by Ann Thorac Surg (373, 4.9\%), Eur 7 Cardiothorac Surg (308, 4.1\%), 7 Vasc Surg (231, 3.1\%), and Interact Cardiovasc Thorac Surg (210, 2.8\%). Figure $2 A$ shows the year-on-year changes in the number of publications of the three major cardiothoracic surgery journals ( 7 Thorac Cardiovasc Surg, Ann Thorac Surg, and Eur 7 Cardiothorac Surg). The publication volume of the three journals was comparable before 2018. After that, the number of AD papers published in 7 Thorac Cardiovasc Surg increased significantly. To be noted, the publication data of 2020 was not complete, as the deadline for data retrieval was July 26, 2020. According to the dependent territory of the journal, most articles were published in United States $(2,676,35.8 \%)$, followed by United Kingdom (1,241, 16.6\%), Netherlands (803, 10.7\%), Japan (620, 8.3\%), Germany (562, 7.5\%), and China (438, $5.9 \%)$. We further analyzed the sources of articles in three major cardiothoracic surgery journals and a Chinese Journal ( 7 Thorac Dis) as a comparison. Out of the 1,164 articles published in the aforementioned four journals, information on first affiliations was successfully extracted in 796 (68.4\%). The top five source countries of $\mathcal{7}$ Thorac Cardiovasc Surg $(\mathrm{n}=244)$, belonging to USA, were Japan $(52,21.3 \%)$, China (35, 14.3\%), Germany (33, 13.5\%), Italy (18, 7.4\%), and USA (18, 7.4\%), respectively; The top five source countries of Ann Thorac Surg ( $\mathrm{n}=248$ ), belonging to USA, were Japan (55, 22.2\%), Germany (31, 12.5\%), China (31, 12.5\%), USA (23, 9.3\%), and Italy (19, 7.7\%), respectively; The top 


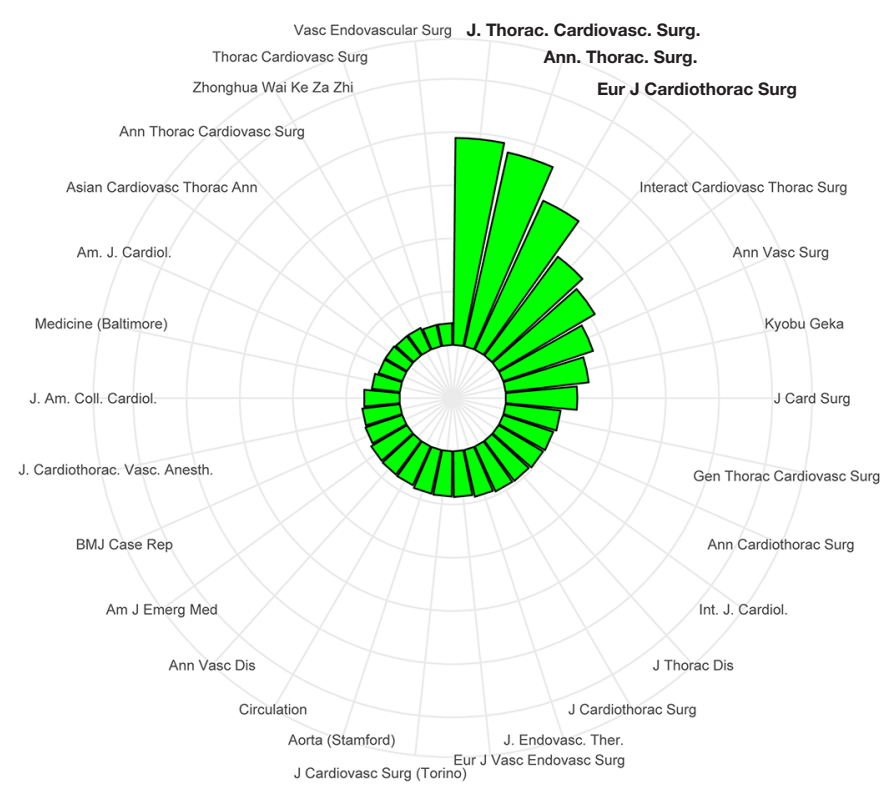

Figure 1 Rose plot displaying the journal ranking by publication numbers of aortic dissection.

five source countries of Eur 7 Cardiothorac Surg ( $\mathrm{n}=215)$, belonging to Germany, were Germany (59, 27.4\%), Japan (44, 20.5\%), USA (23, 10.7\%), China (22, 10.2\%), and Switzerland (12, 5.6\%), respectively. The top five source countries of $\mathcal{F}$ Thorac Dis ( $\mathrm{n}=89)$, belonging to China, were China (53, 60.0\%), USA (8, 9.0\%), Japan (5, 5.6\%), South Korea (5, 5.6\%), and Germany (3, 3.4\%), respectively. As demonstrated above, the three major cardiothoracic surgery journals were highly internationalized, with balanced sources. No obvious regional publication discrimination or tendency was found. As a relatively "young" journal, $\mathcal{f}$ Thorac Dis still needs time to grow.

In terms of publication types of those 7,470 articles, Journal Article accounted for the majority (4,181, 55.9\%), followed by Case Reports $(2,250,30.1 \%)$, Comparative Study (365, 4.8\%), Editorial (197, 2.6\%), Letter (187, $2.5 \%)$, etc. We further analyzed the article types of the three major cardiothoracic surgery journals (Figure 2B). As expected, Journal Article was the most common type, especially for Eur 7 Cardiothorac Surg. 7 Thorac Cardiovasc Surg published more Editorials while Ann Thorac Surg published more Case Reports compared to others. This information may be helpful to guide researchers to choose the appropriate journal according to the article type. It is worth noting that from the 7,470 articles, only 10 clinical trials $(0.5 \%)$ were found based on the article type marked by PubMed. The basic information of these 10 clinical trials was shown in Table 1. Most of the clinical trials were published on 7 Vasc Surg (4, 40\%), followed by Ann Thorac Surg (2, 20\%). The USA contributed $5(50 \%)$ clinical trials, followed by the United Kingdom (2, 20\%), Canada (2, $20 \%$ ) and Germany (1,10\%). Most clinical trials focused on endovascular treatment of type B dissection $(6,60 \%)$, and hybrid operation for type A dissection (2,20\%). The total number of citations of these 10 clinical trials was 88 , and the endovascular treatment of type B dissection accounted for up to $78(88.6 \%)$ citations.

To demonstrate the most influential and active researchers in this field, we first counted the publication numbers by individual researchers (first and senior author) in the past decade (Figure 3A). John A. Elefteriades ranked first, followed by Christoph A. Nienaber and Lizhong Sun. Of note, two female researchers also entered the top 30 list regarding publication numbers: Ourania Preventza and Dianna M. Milewicz. Specifically, the top 10 female researchers by publication numbers were Ourania Preventza, Dianna M. Milewicz, Jolien W Rooshesselink, Rossella Fattori, Rachel E. Clough, Elizabeth L. Norton, Akiko Tanaka, Jennifer S. Lawton, Julie De Backer, and Sherene Shalhub. Next, we ranked the researchers according to the cumulative number of citations (Figure 3B), with Raimund Erbel being the first, Ivan Kravchenko the second, and Christoph A. Nienaber the third. The most frequently cited article in the AD field is the 2014 


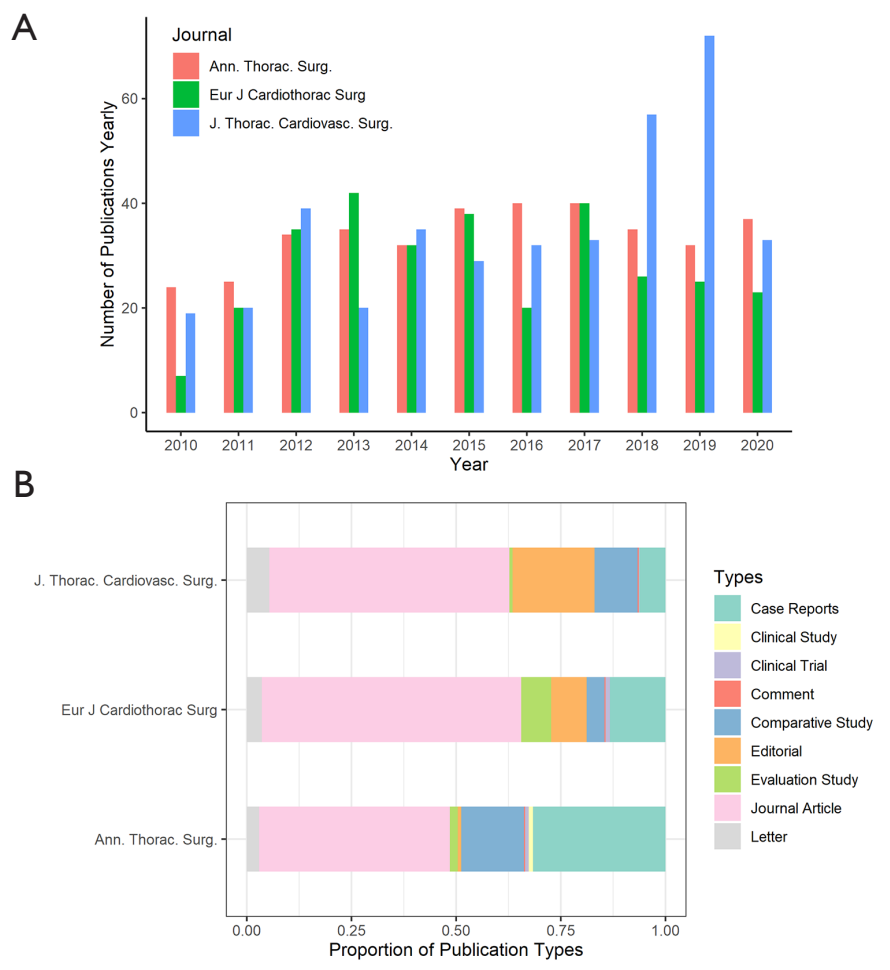

Figure 2 Publication data of the three major cardiovascular surgery journals. (A) Year-on-year changes in the number of publications of the three major cardiothoracic surgery journals (7 Thorac Cardiovasc Surg, Ann Thorac Surg, and Eur 7 Cardiothorac Surg). (B) The proportion of publication types of the three major cardiothoracic surgery journals ( $\mathcal{F}$ Thorac Cardiovasc Surg, Ann Thorac Surg, and Eur $\mathcal{F}$ Cardiothorac Surg).

ESC Guidelines on the diagnosis and treatment of aortic diseases, a product of the collective effort by a group of extraordinary aortic experts (2). So, we made another ranking by excluding this Guideline to eliminate the potential biased effect on the individual ranking of citations. In the updated ranking, Christoph A. Nienaber stood in the first place, followed by Dianna M. Milewicz and John A. Elefteriades. Although not $100 \%$ perfect, the impact factor is still an important measure of the journal level and the difficulty of publication, so we also ranked the researchers according to their cumulative impact factors (Figure 3C). Christoph A. Nienaber took the first place, followed by Kim A. Eagle, and John A. Elefteriades. A total of 13 researchers were on all the three lists (top 30) by publication numbers, cumulative citations, and cumulative impact factors: John A. Elefteriades, Christoph A. Nienaber, Lizhong Sun, Yutaka Okita, Zaiping Jing, Joseph S. Coselli, Bartosz Rylski, Martin Czerny, Santi Trimarchi, Kim A. Eagle, Scott A. Lemaire, Dianna M. Milewicz, and G. Chad Hughes. Of note, John A. Elefteriades and Christoph A. Nienaber were the only two researchers entering all the three lists (top 3) by either publication numbers, cumulative citations, or cumulative impact factors. What's more, we also made a chord graph to show the authors' collaboration network (Figure 3D). If the number of collaborative articles between the two authors was greater than 15 , they would appear on this network. The more cooperations between two authors, the thicker the connection.

We extracted the first affiliations from the 7,470 articles and mapped them geographically (Figure $4 A$ ). The darker the color, the greater the number of publications. Japan stands in the first place regarding publication volume, followed by China, USA, Germany, and Italy. Since the number of citations can comprehensively reflect the influence and spread of an article, we listed the top 10 articles with the highest citation rates in the past decade (Table 2) and provided the top 100 articles with the highest citation rates in the Table S1. We further marked the institutions where the top 100 most cited articles were from on the map according to the city coordinates (Figure $4 B$ ). 
Table 1 Clinical trials in recent 10 years regarding aortic dissection

\begin{tabular}{|c|c|c|c|c|c|c|}
\hline PMID & Titles & Journal & Year & $\begin{array}{l}\text { Impact } \\
\text { factor }\end{array}$ & First author & First affiliation \\
\hline 20807993 & $\begin{array}{l}\text { External aortic root support for Marfan syndrome: } \\
\text { early clinical results in the first } 20 \text { recipients with a } \\
\text { bespoke implant }\end{array}$ & $J R$ Soc Med & 2010 & 5.238 & John Pepper & $\begin{array}{c}\text { Royal Brompton } \\
\text { Hospital }\end{array}$ \\
\hline 22169668 & $\begin{array}{l}\text { Prospective multicenter clinical trial (STABLE) on } \\
\text { the endovascular treatment of complicated type B } \\
\text { aortic dissection using a composite device design }\end{array}$ & $J$ Vasc Surg & 2011 & 3.405 & $\begin{array}{l}\text { Joseph V. } \\
\text { Lombardi }\end{array}$ & $\begin{array}{c}\text { Cooper University } \\
\text { Hospital }\end{array}$ \\
\hline 23800455 & $\begin{array}{l}\text { Fenestrated and branched endovascular aortic } \\
\text { repair for chronic type B aortic dissection with } \\
\text { thoracoabdominal aneurysms }\end{array}$ & J Vasc Surg & 2013 & 3.405 & Atsushi Kitagawa & $\begin{array}{l}\text { Cleveland Clinic } \\
\text { Foundation }\end{array}$ \\
\hline 24560244 & $\begin{array}{l}\text { Aortic remodeling after endovascular treatment of } \\
\text { complicated type B aortic dissection with the use } \\
\text { of a composite device design }\end{array}$ & J Vasc Surg & 2014 & 3.405 & $\begin{array}{l}\text { Joseph V. } \\
\text { Lombardi }\end{array}$ & $\begin{array}{c}\text { Cooper University } \\
\text { Hospital }\end{array}$ \\
\hline 25669649 & $\begin{array}{l}\text { Do not leave the heart arrested. Non-cardioplegic } \\
\text { continuous myocardial perfusion during complex } \\
\text { aortic arch repair improves cardiac outcome }\end{array}$ & $\begin{array}{c}\text { Eur J } \\
\text { Cardiothorac Surg }\end{array}$ & 2015 & 3.486 & Andreas Martens & $\begin{array}{c}\text { Hannover } \\
\text { Medical School }\end{array}$ \\
\hline 26209487 & $\begin{array}{l}\text { Outcomes of Thoracic Endovascular Aortic Repair } \\
\text { in Acute Type B Aortic Dissection: Results From } \\
\text { the Valiant United States Investigational Device } \\
\text { Exemption Study }\end{array}$ & Ann Thorac Surg & 2015 & 3.639 & Joseph E. Bavaria & $\begin{array}{l}\text { University of } \\
\text { Pennsylvania }\end{array}$ \\
\hline 26211376 & $\begin{array}{l}\text { Multicenter clinical trial of the conformable stent } \\
\text { graft for the treatment of acute, complicated type } \\
\text { B dissection }\end{array}$ & $J$ Vasc Surg & 2015 & 3.405 & $\begin{array}{l}\text { Richard P. } \\
\text { Cambria }\end{array}$ & $\begin{array}{l}\text { Massachusetts } \\
\text { General Hospital }\end{array}$ \\
\hline
\end{tabular}

The larger the red circle, the more articles with a high citation rate were published in a specific area. It shows that almost all the highly cited papers were from the USA and Europe. The USA was far ahead of other countries regarding the highly cited studies, especially the East. Institutions with 3 or more highly cited articles included Yale University, Baylor College of Medicine, Erasmus University Medical Center, Fondazione RiMED, Mayo Clinic, University of Pennsylvania, University of Rostock, and University of Texas.

We further analyzed the correlation between impact factors and citation times, and found that there was a positive correlation between them (Pearson index: 0.31,
95\% CI: $0.28-0.33, \mathrm{P}<0.001)$. We listed the top 10 articles with the highest impact factor in Table 3 and the top 100 as Table S2.

Next, we extracted the keywords and removed those words that were obviously highly frequent such as "aortic dissection", "aortic aneurysm", etc., and then calculated the frequency of the keywords. As shown in Figure 5, word frequency was presented in the form of a word cloud. The higher the word frequency is, the larger the area it occupies in the word cloud. During 2010 and 2014, the top 10 keywords were Treatment Outcome, Retrospective Studies, Risk Factors, Blood Vessel Prosthesis Implantation, Tomography (X-ray computed), Endovascular Procedures, 


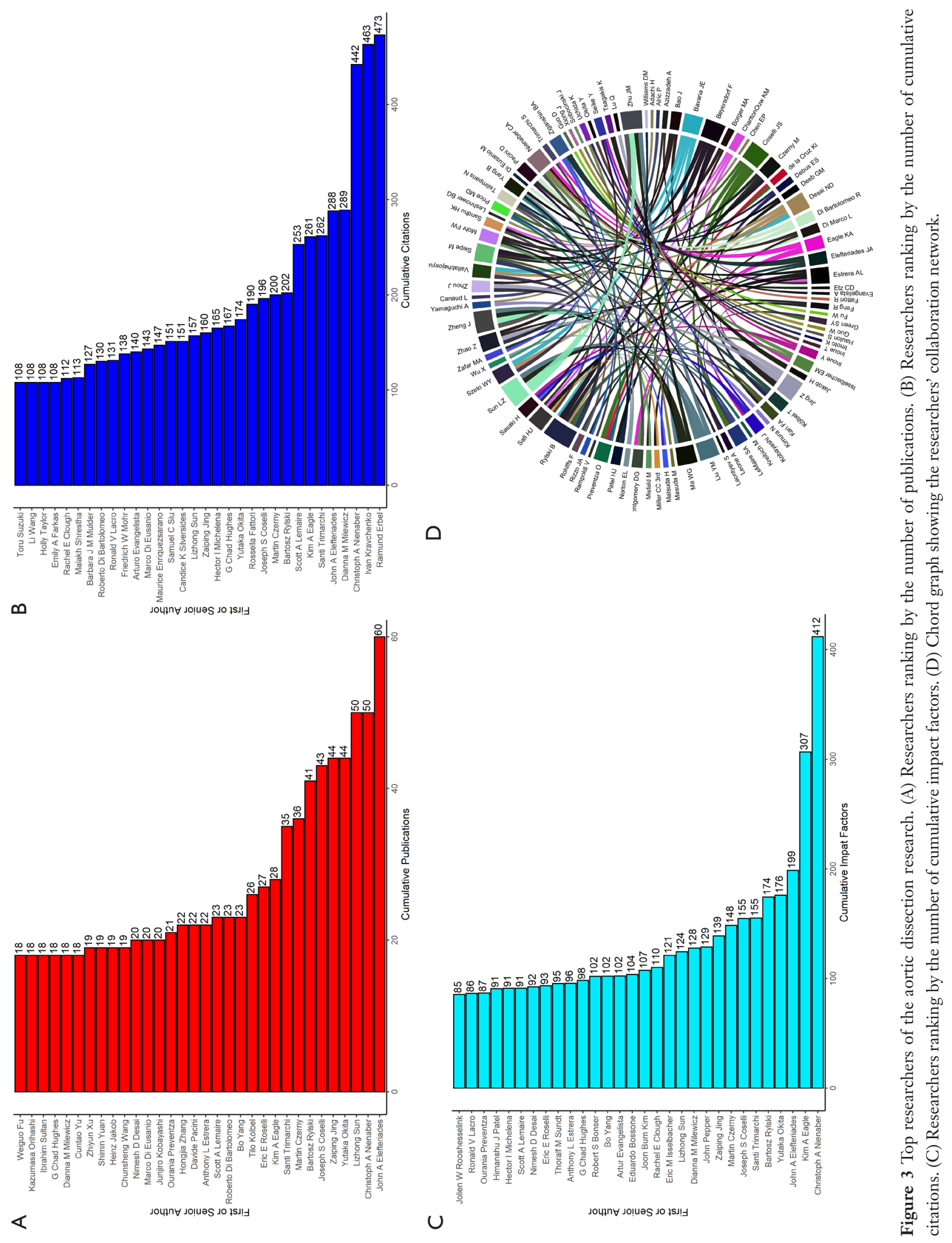



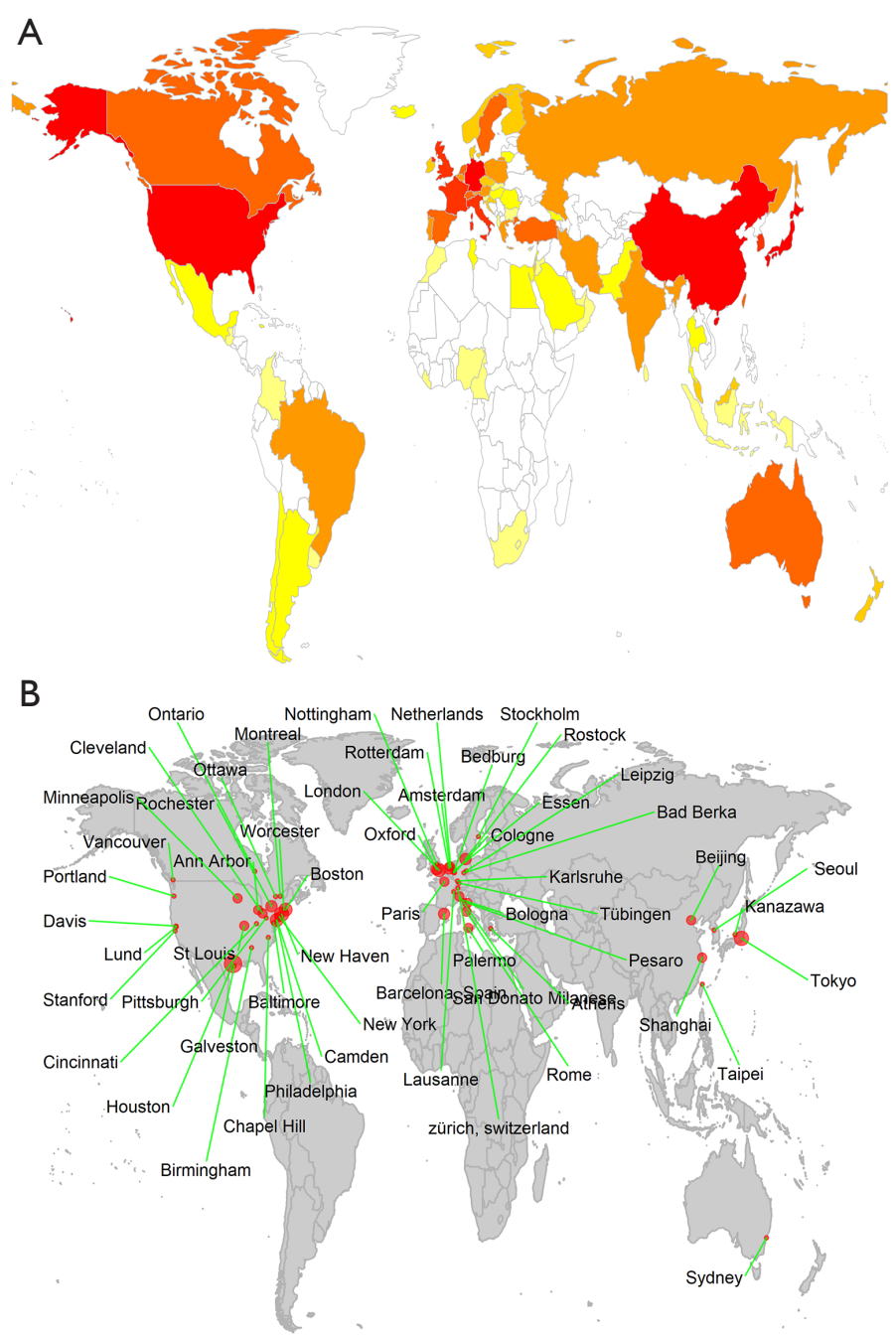

Figure 4 Geographical demonstration of the aortic dissection research. (A) World map showing the countries ranking by the number of publications. (B) World map showing the geographical distribution of the highly cited publications (top 100).

Stents, Aortography, Hospital Mortality, and Postoperative Complications. During 2015 and 2020, the top ten keywords were Retrospective Studies, Treatment Outcome, Risk Factors, Blood Vessel Prosthesis Implantation, Endovascular Procedures, Postoperative Complications, Stents, Blood Vessel Prosthesis, Computed Tomography Angiography, and Follow-Up Studies. To a certain extent, keyword frequency can reflect the research direction and hot spots in this field. We found that the research direction of AD had little change in the past decade. Most of the researches were about Treatment Outcome, Risk Factors, Blood Vessel Prosthesis Implantation, and the main research method was Retrospective Studies.

\section{Comment}

This study provides interesting insights into $\mathrm{AD}$ scientific landscape in recent 10 years by identifying many "firsts" or "mosts" as follows: most of the articles were published in 7 Thorac Cardiovasc Surg; Japan was the country with the largest publications number; the USA was far ahead of other countries regarding the highly cited studies; Yale University and Baylor College of Medicine took the first prize for publishing most of the highly cited articles; Journal Article was the most common article type; the most frequently cited article was the 2014 ESC Guidelines on the diagnosis and treatment of aortic diseases (2); most of the clinical trials were published on 7 Vasc Surg; John A. Elefteriades 
Table 2 Top 10 articles ranked by impact factor during 2010-2020 regarding aortic dissection

\begin{tabular}{|c|c|c|c|c|c|c|}
\hline PMID & Titles & Journal & Year & $\begin{array}{l}\text { Impact } \\
\text { factor }\end{array}$ & First author & Citations \\
\hline 20872991 & $\begin{array}{l}\text { Images in clinical medicine. Aortic dissection during } \\
\text { diagnostic aortography }\end{array}$ & N Engl J Med & 2010 & 74.699 & Samad Ghaffari & 1 \\
\hline 25229939 & Images in clinical medicine. Aortic dissection & N Engl J Med & 2014 & 74.699 & Amritpal Singh Nat & 0 \\
\hline 25405392 & $\begin{array}{l}\text { Atenolol versus losartan in children and young } \\
\text { adults with Marfan's syndrome }\end{array}$ & N Engl J Med & 2014 & 74.699 & Ronald V. Lacro & 108 \\
\hline 25662791 & Management of acute aortic dissection & Lancet & 2015 & 60.392 & Christoph A. Nienaber & 61 \\
\hline 21917581 & $\begin{array}{l}\text { Incidence of aortic complications in patients with } \\
\text { bicuspid aortic valves }\end{array}$ & JAMA & 2011 & 45.54 & Hector I. Michelena & 122 \\
\hline 27533160 & $\begin{array}{l}\text { Acute Aortic Dissection and Intramural Hematoma: } \\
\text { A Systematic Review }\end{array}$ & $J A M A$ & 2016 & 45.54 & Firas F. Mussa & 34 \\
\hline 27440162 & Aortic dissection & Nat Rev Dis Primers & 2016 & 40.689 & Christoph A. Nienaber & 19 \\
\hline 27440218 & Aortic dissection & Nat Rev Dis Primers & 2016 & 40.689 & - & 0 \\
\hline 27560366 & Aortic dissection & Nat Rev Dis Primers & 2016 & 40.689 & Christoph A. Nienaber & 2 \\
\hline
\end{tabular}

ranked first by cumulative publication numbers; Christoph A. Nienaber took the lead by both cumulative citations and impact factors; Dianna M. Milewicz was the only female researcher on all the three ranking lists; The most common keywords in aortic dissection were Treatment Outcome and Retrospective Studies, etc.

According to the literature we searched, most $\mathrm{AD}$ researches are of a low hierarchy of evidence, with few clinical trials. As can be seen from the word cloud, most of the studies are retrospective, focusing on treatment outcome and risk factors. There are many problems to be solved in $\mathrm{AD}$ management, such as total arch replacement versus half arch replacement, unilateral perfusion versus bilateral perfusion, optimal circulatory arrest temperature, etc. Only high-quality data and research can provide convincing answers and promote the standardization of $\mathrm{AD}$ management. Admittedly, $\mathrm{AD}$ is a highly urgent and variable disorder, which makes it very difficult to carry out clinical trials. In recent ten years, there are only two Guidelines $(2,3)$ for aortic disease, and both of them were put forward at least 6 years ago. Compared to other areas of cardiology or cardiac surgery, the Guideline update for the aortic disease is relatively slow, which might be partially due to the lack of high-level evidence that can influence clinical practice.

Notably, the International Registry of Acute Aortic Dissection (IRAD), the world's largest and most famous database of aortic dissection including 55 active sites in 12 countries, has set a benchmark and paradigm for the study of AD. Among the top 100 highly cited studies, IRAD contributed up to 11 articles! Prompted by IRAD, some other registered multi-center studies have also been launched such as the German Registry for Acute Aortic Dissection type A (GERAADA), Nordic Consortium for Acute Type A Aortic Dissection (NORCAAD), Gore Global Registry for Endovascular Aortic Treatment (GREAT), and International Aortic Arch Surgery Study Group (IAASG), etc. GERAADA also contributed 3 articles in the top 100 highly cited studies. These registered multi-center studies will certainly continue to greatly influence the way we treat aortic dissection worldwide. There is a large number of publications from Asia, especially China and Japan, but few highly cited works were generated. In the future, these high-volume regions may consider how to translate their large sample size to high-impact research, with IRAD as a good model.

In addition, the researches of $\mathrm{AD}$ mainly focus on the treatment, especially endovascular treatment. The 
Table 3 Top 10 most cited articles during 2010-2020 regarding aortic dissection

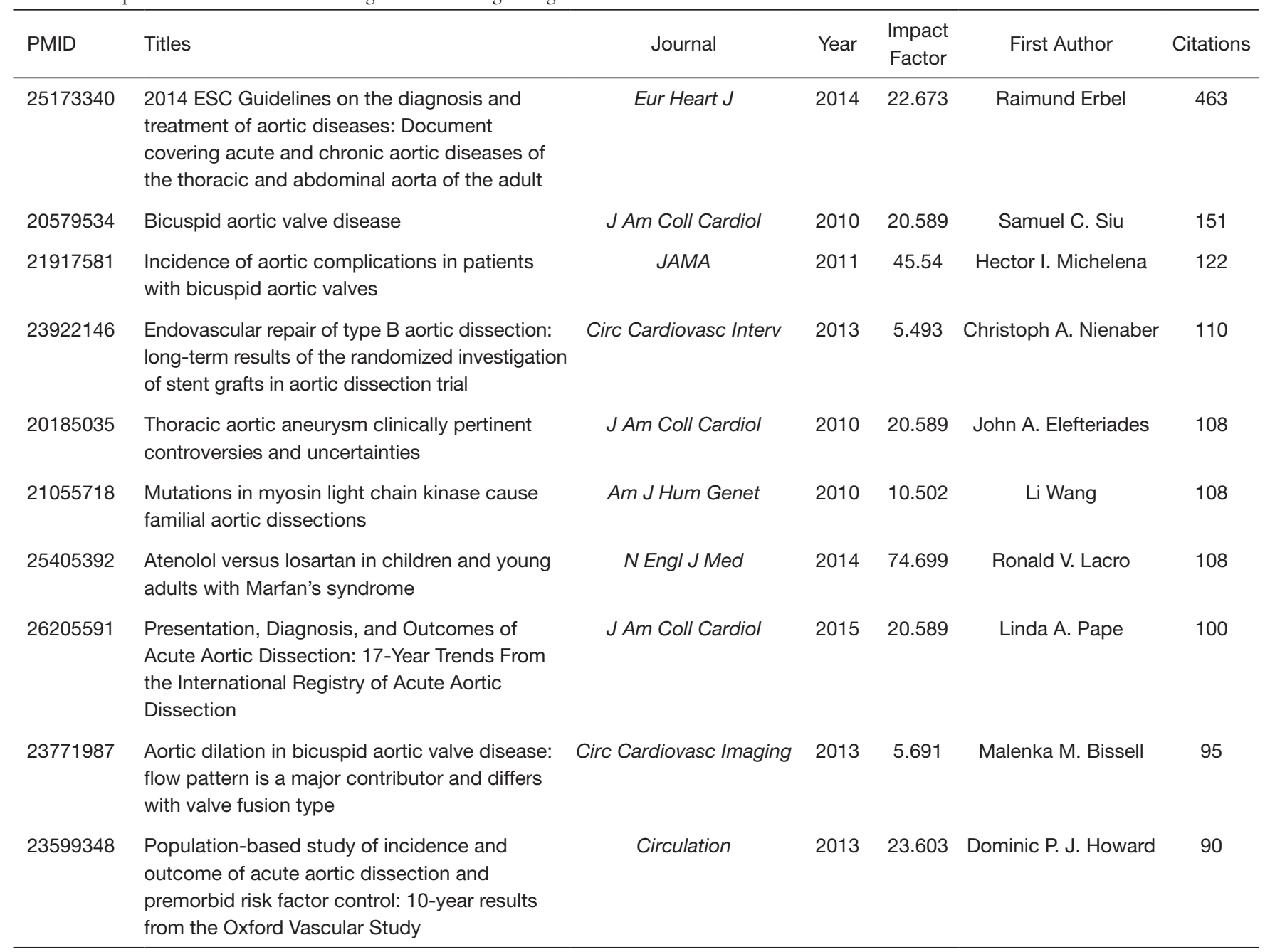

management of $\mathrm{AD}$ involves many aspects. In addition to treatment, we also need to investigate more on the epidemiology, prevention, diagnosis, and perioperative management. Among these retrieved studies, clinical research accounts for the vast majority, while basic researches are relatively rare (the top 10 frequent keywords are basically all clinical research related, and basic research only accounts for $33 / 105$ (31.4\%) of the highly cited papers). It remains unclear of the pathogenesis of aortic dissection, and no effective molecule- or pathway-targeted interventions were established. More investment in basic research is needed in the future.

Strikingly, we found that only a small proportion of aortic researchers were women. Although we cannot directly provide data on the proportion of male and female researchers in this study, out of the top 30 researchers by publication numbers, only two $(2 / 32,6.2 \%)$ are women (Ourania Preventza and Dianna M Milewicz). It was reported that (4) in the United States and Europe, women comprise at least $50 \%$ of medical graduates. Despite gender balance among medical trainees, only one-third of practicing physicians, and $<20 \%$ of cardiology trainees are women. The gender gap is supposed to be even wider in aortic disease considering the higher work intensity. The gender gap in $\mathrm{AD}$ has potential adverse impacts on collegial support, mentoring, research and even patients outcomes, etc. Improving gender equality within cardiology has been identified as a powerful means to improve cardiovascular disease outcomes in women- "Small Numbers, Big Impact" (5). For example, our study shows that Dianna M. Milewicz 
A
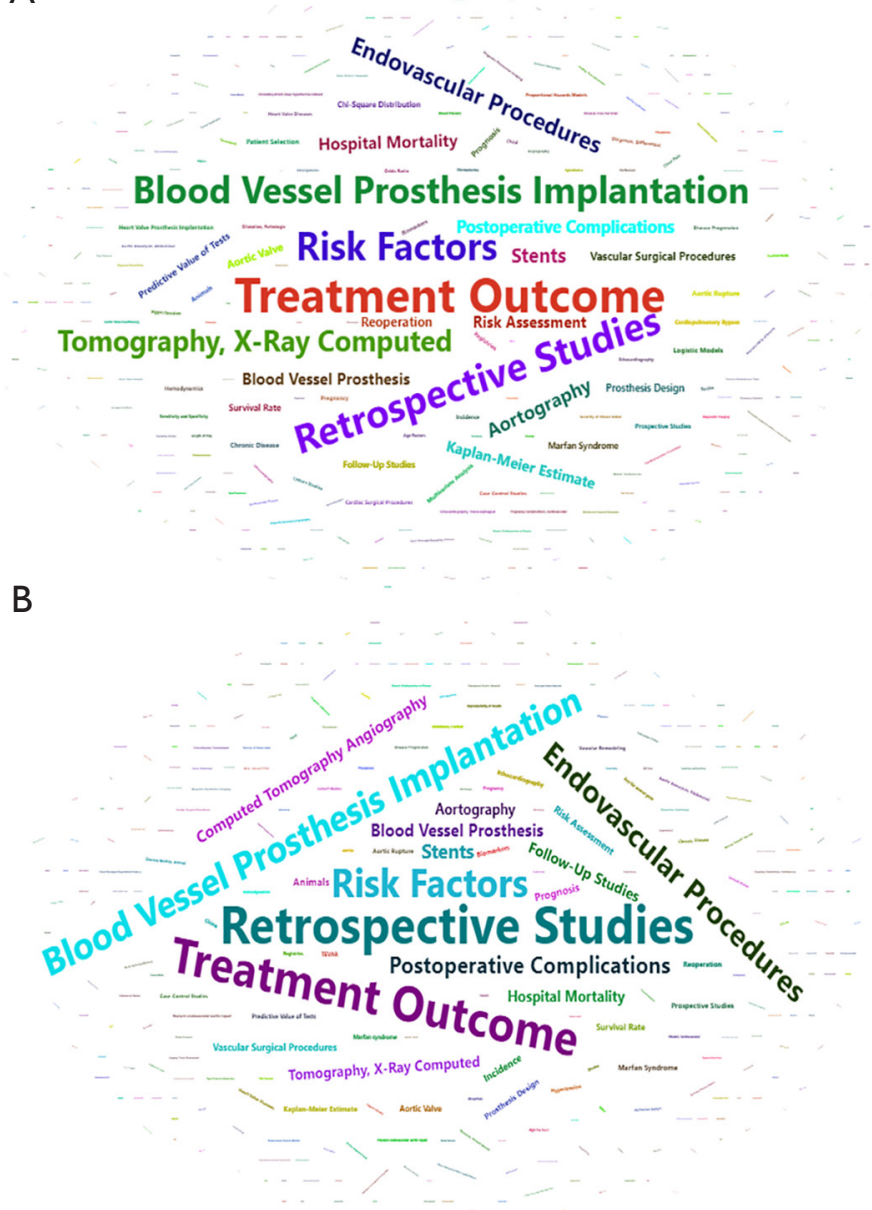

Figure 5 Word cloud of the key words. (A) Word cloud displaying the keyword frequencies between 2010-2014. (B) Word cloud displaying the keyword frequencies between 2015-2020.

as the only female in all the three ranking list (publication numbers, citations, impact factors), has been one of the mainstays in decoding the genetic predisposition to vascular diseases. As Burgess et al. have proposed, we must encourage a dialogue to identify barriers and provide potential solutions to empower more women to join this highly rewarding specialty (4).

\section{Limitations}

Our study should be interpreted in the context of several limitations. First, the cited rate is one of the most important tools in bibliometrics. However, it's very hard for the newly published studies to have high citations regardless of its significance because of the limited exposure. So, bibliometrics should be a dynamic analysis tool and subject to regular updates. Second, to confirm the ratio of male and female researchers, we have tried many programs and websites that were claimed to be able to automatically identify gender by name, but the accuracy was very poor. Hopefully, there will be more accurate and efficient methods to match the name and gender in the future. Third, due to the diversity of institutions naming, we had no way to accurately rank all the institutions. Instead, we sorted institutions by the list of the top 100 most cited studies manually and mapped them. The results were consistent with our knowledge of the leading institutions in this field. 


\section{Conclusions}

In this study, we performed a bibliometric analysis of $\mathrm{AD}$ in the recent ten years and many "firsts" or "mosts" have been identified, providing some objective evidence for comprehensive understanding and evaluation of this field, which might ultimately inform managers, researchers and policymakers.

\section{Acknowledgments}

JW would like to especially thank Dr. Daoyuan Wang from AME Publishing Company for incidentally inspiring the study. JW would also like to thank Yan Huang for her long support.

Funding: This work was supported by the National Key R\&D Program of China (2018YFC1002600) and the Science and T echnology Planning Project of Guangdong Province, China (2017A070701013, 2017B090904034, 2017B030314109, 2019B020230003) and the Guangdong peak project (DFJH201802).

\section{Footnote}

Conflicts of Interest: All authors have completed the ICMJE uniform disclosure form (available at http://dx.doi. org/10.21037/jtd-20-3272). The authors have no conflicts of interest to declare.

Ethical Statement: The authors are accountable for all aspects of the work in ensuring that questions related to the accuracy or integrity of any part of the work are appropriately investigated and resolved. The study was approved by the Chinese Ethics Committee of Registering Clinical Trials (ChiECRCT-20180041), with informed consent waived.

Cite this article as: $\mathrm{Wu} \mathrm{J}$, Zhao R, Zhuang D, Zhu J, Zheng H, Chen J. The recent 10-year landscape of aortic dissection research: a bibliometric analysis. J Thorac Dis 2021;13(3):15921602. doi: $10.21037 /$ jtd-20-3272
Open Access Statement: This is an Open Access article distributed in accordance with the Creative Commons Attribution-NonCommercial-NoDerivs 4.0 International License (CC BY-NC-ND 4.0), which permits the noncommercial replication and distribution of the article with the strict proviso that no changes or edits are made and the original work is properly cited (including links to both the formal publication through the relevant DOI and the license). See: https://creativecommons.org/licenses/by-nc-nd/4.0/.

\section{References}

1. DeMartino RR, Sen I, Huang Y, et al. PopulationBased Assessment of the Incidence of Aortic Dissection, Intramural Hematoma, and Penetrating Ulcer, and Its Associated Mortality From 1995 to 2015. Circ Cardiovasc Qual Outcomes 2018;11:e004689.

2. Erbel R, Aboyans V, Boileau C, et al. 2014 ESC Guidelines on the diagnosis and treatment of aortic diseases:

Document covering acute and chronic aortic diseases of the thoracic and abdominal aorta of the adult. The Task Force for the Diagnosis and Treatment of Aortic Diseases of the European Society of Cardiology (ESC). Eur Heart J 2014;35:2873-26. Correction appears in Eur Heart J 2015;36:2779.

3. JCS Joint Working Group. Guidelines for diagnosis and treatment of aortic aneurysm and aortic dissection (JCS 2011): digest version. Circ J 2013;77:789-828.

4. Burgess S, Shaw E, Ellenberger K, et al. Women in Medicine: Addressing the Gender Gap in Interventional Cardiology. J Am Coll Cardiol 2018;72:2663-7.

5. Abbott JD. Women in Interventional Cardiology: Small Numbers, Big Impact. Circ Cardiovasc Interv 2016;9:e04323. 


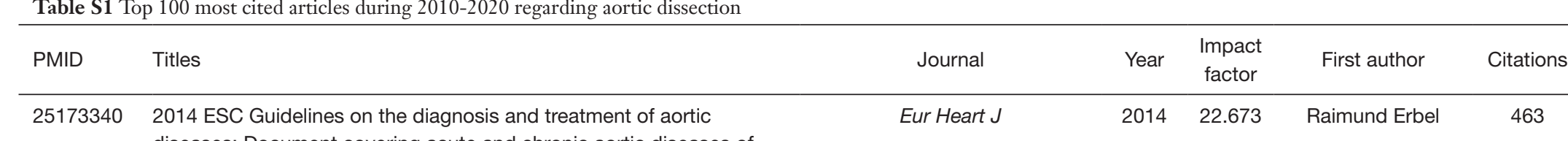

tant

inn

ate

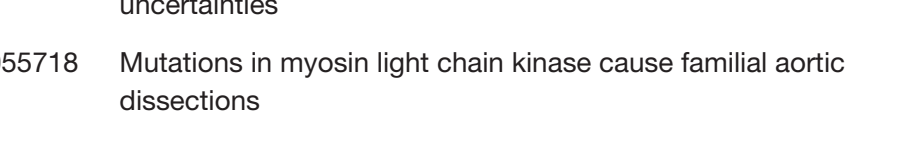

and

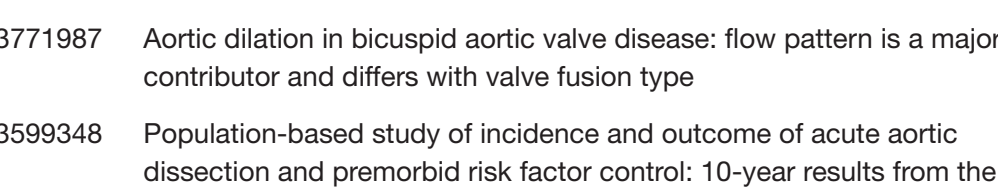

tesos

mox

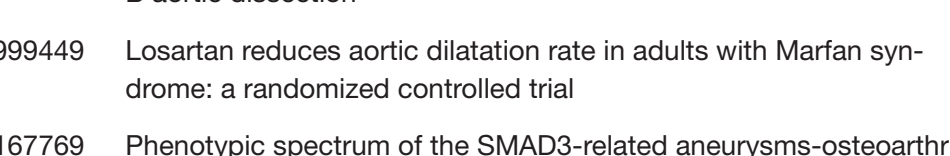

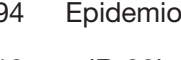

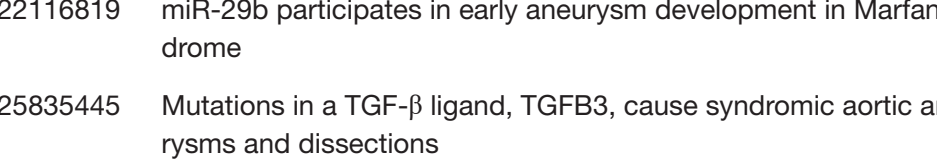

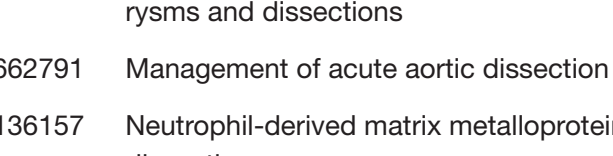

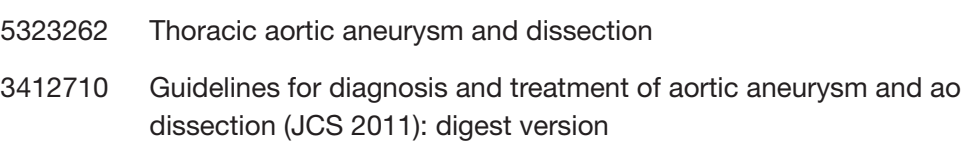

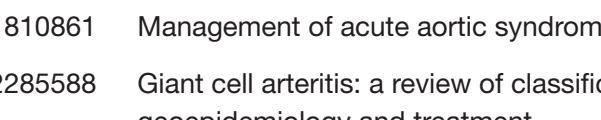

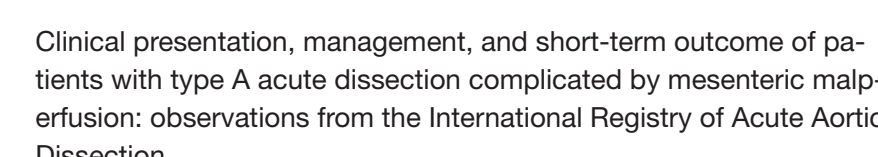

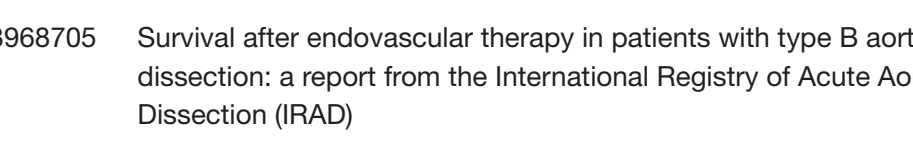

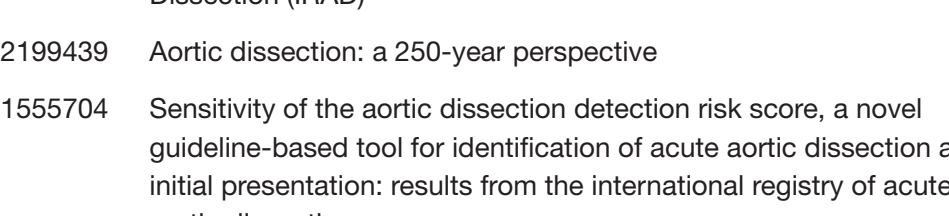

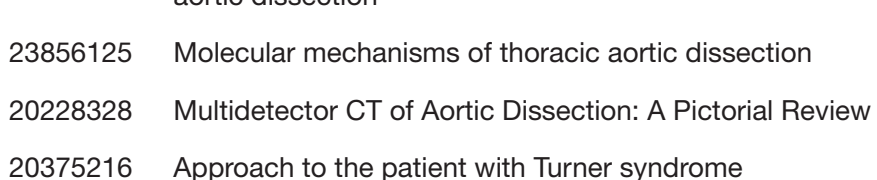

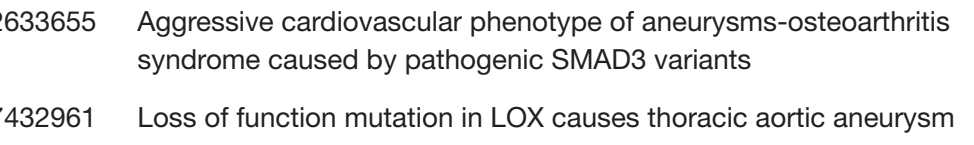

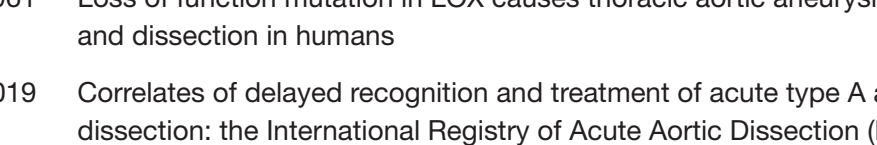

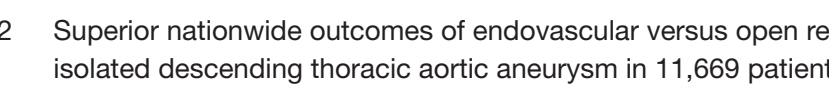

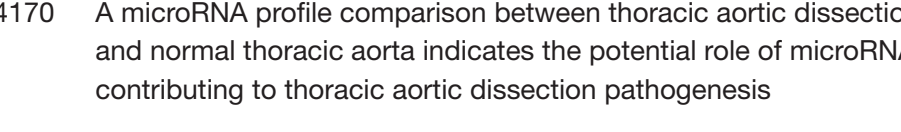

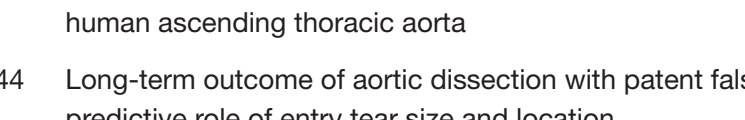

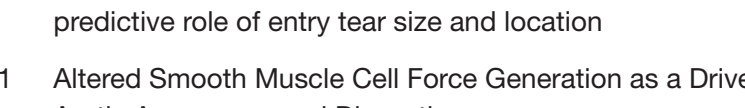

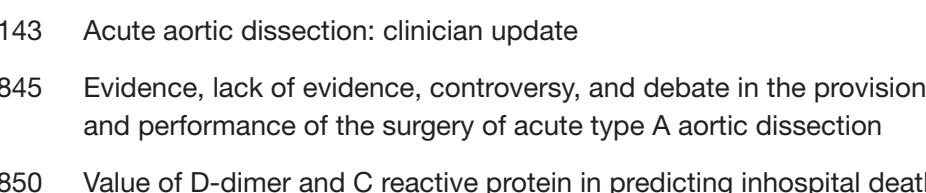

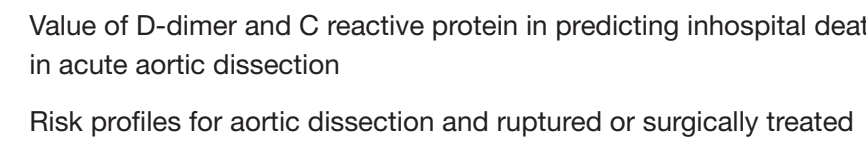

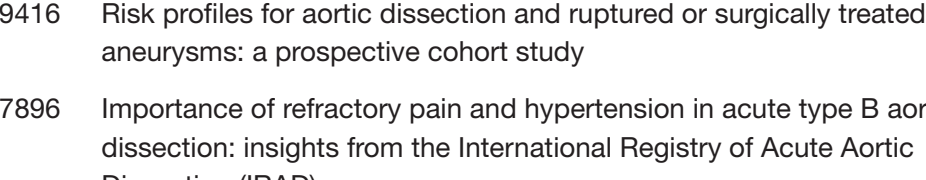

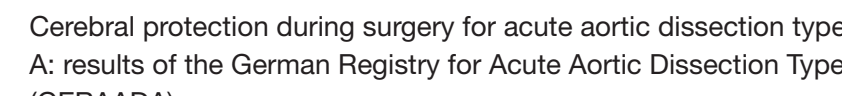

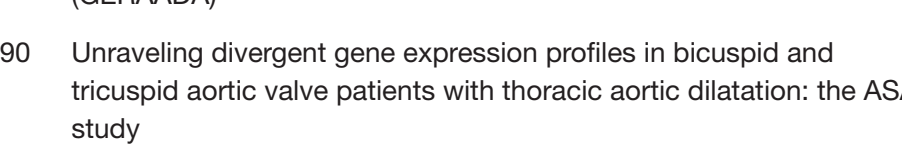

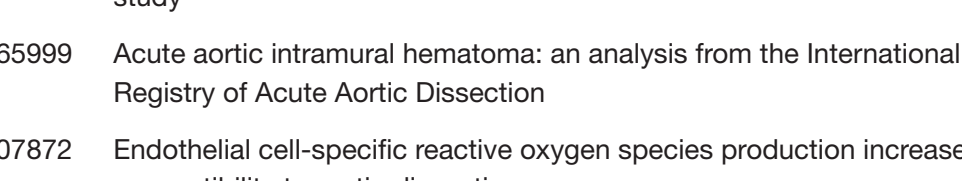

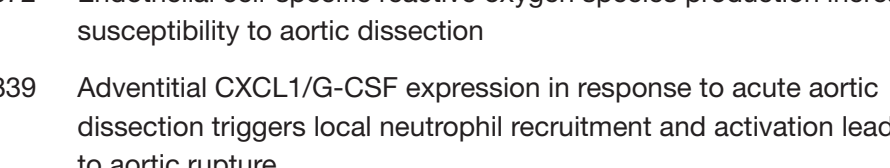

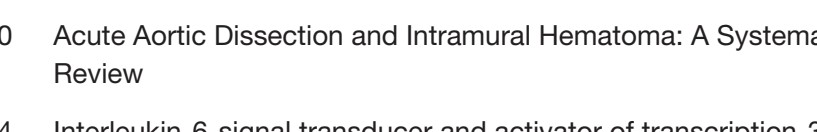

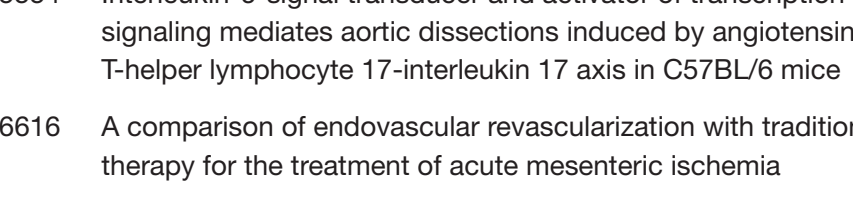

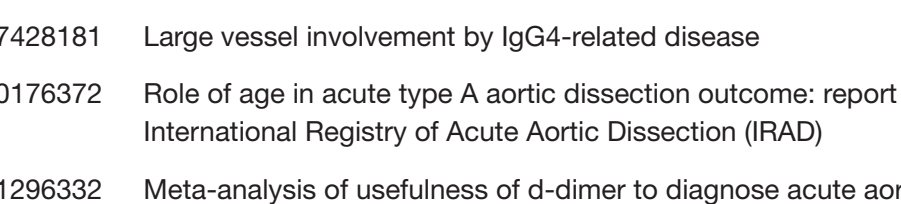

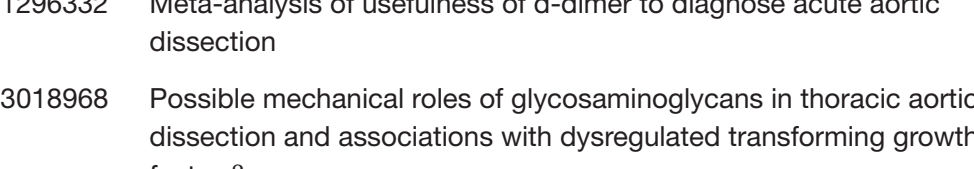

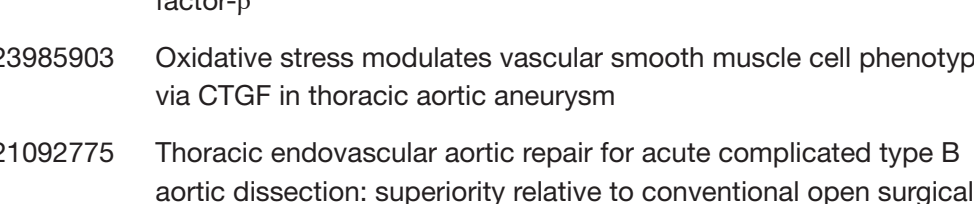

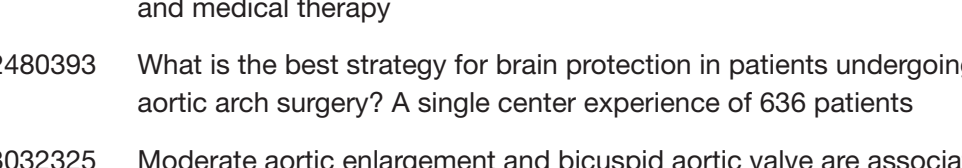

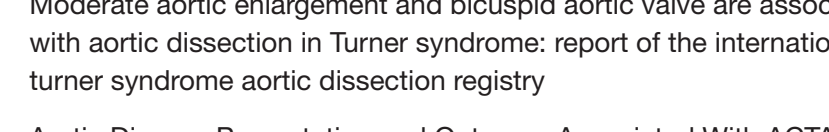

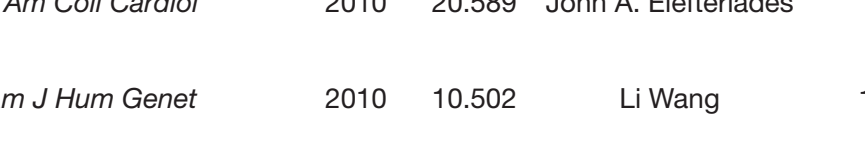

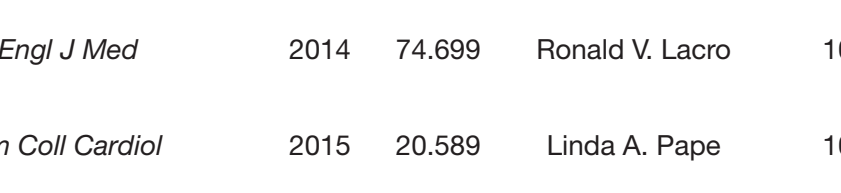

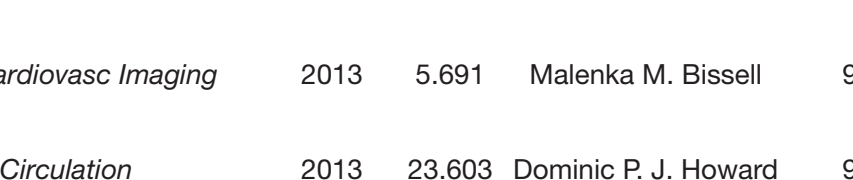

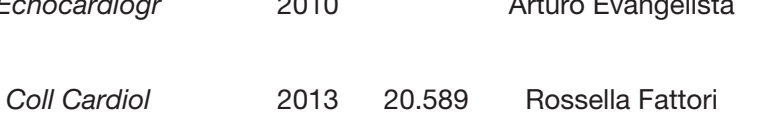

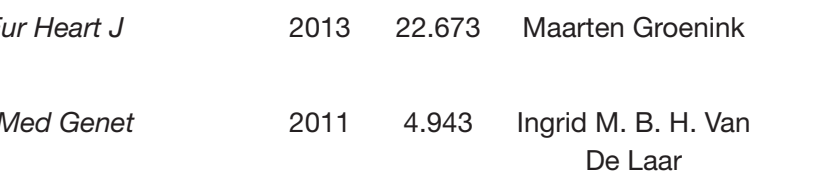

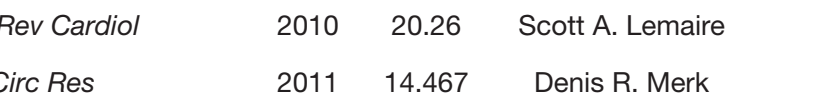

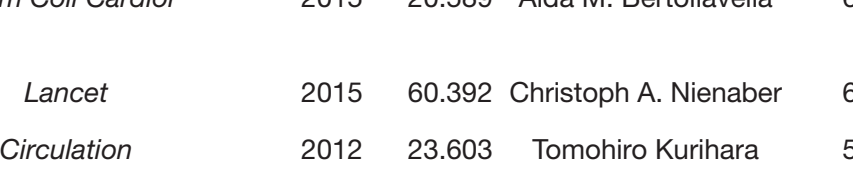

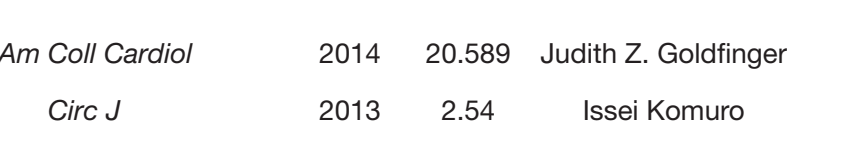

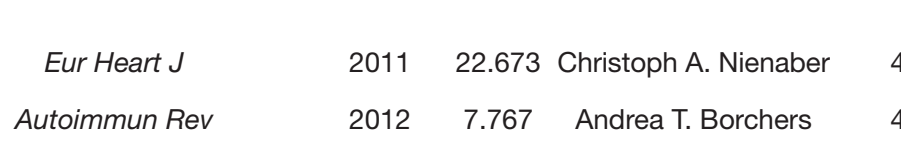

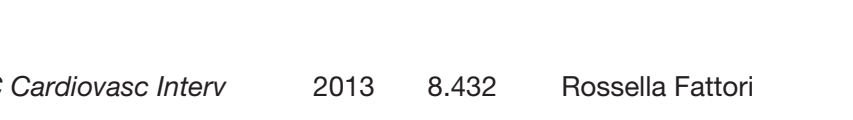

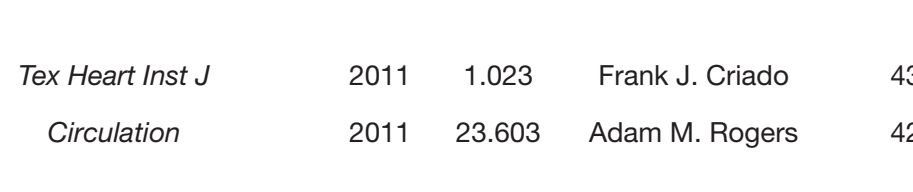

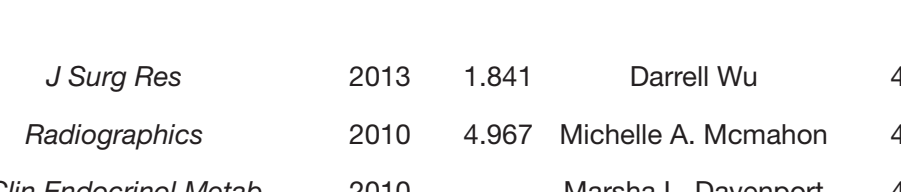

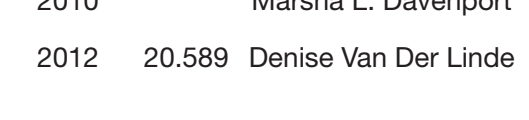

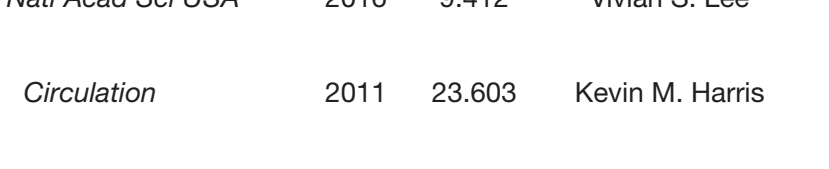

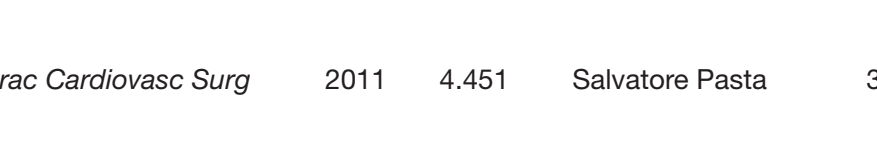

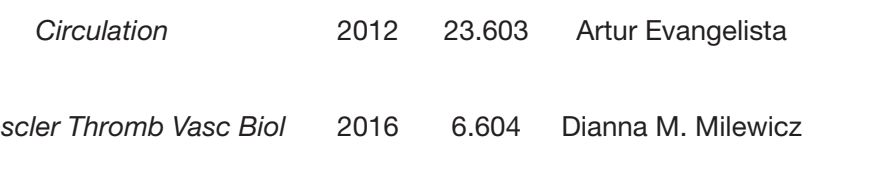

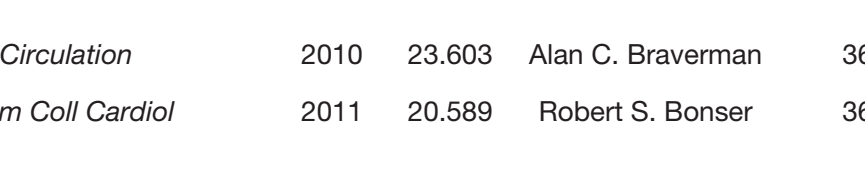

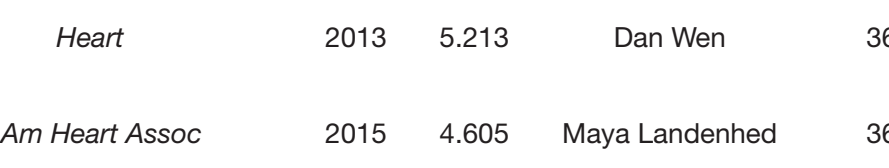

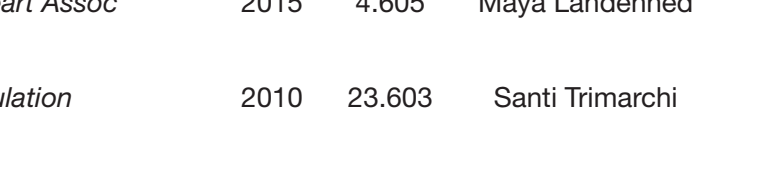

$\begin{array}{llll}2011 & 23003 & \text { Todias kriger }\end{array}$

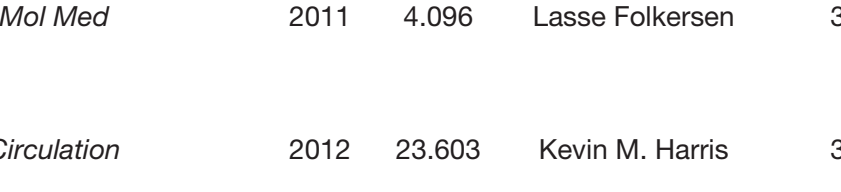

2014

una

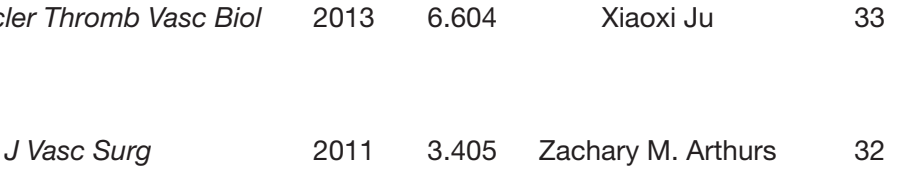

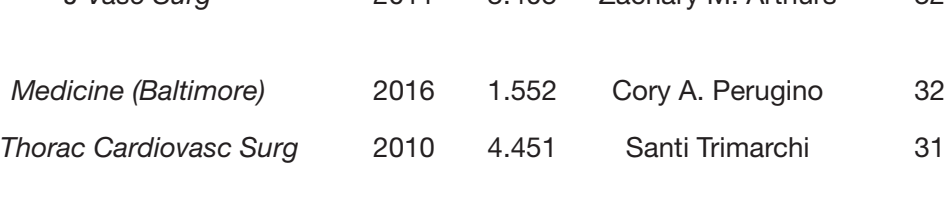

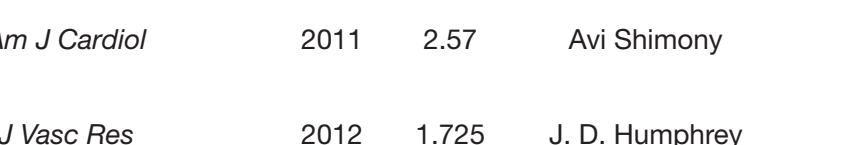

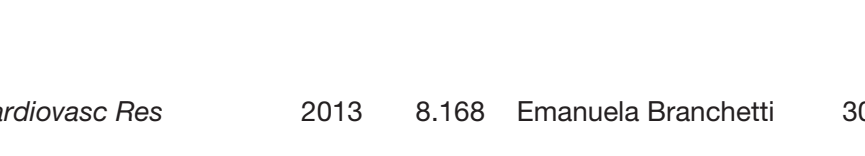

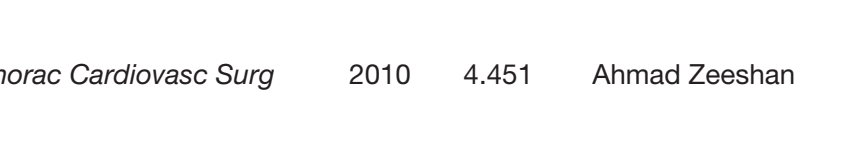

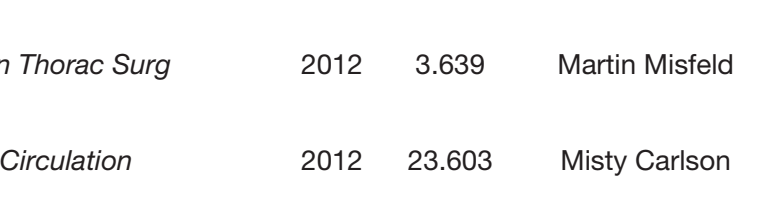

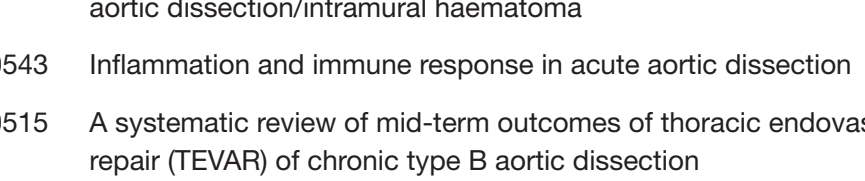

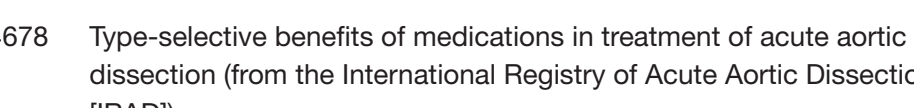

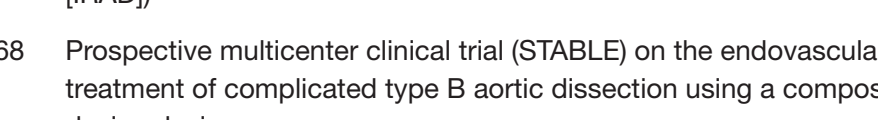

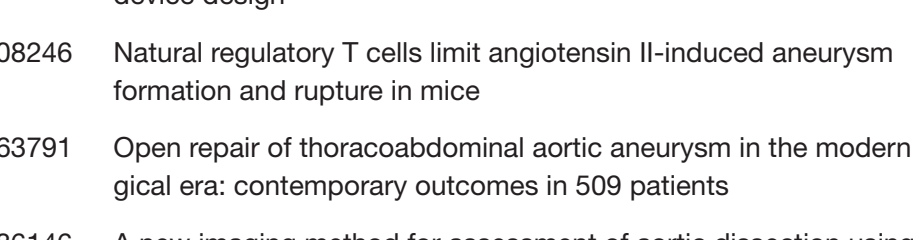

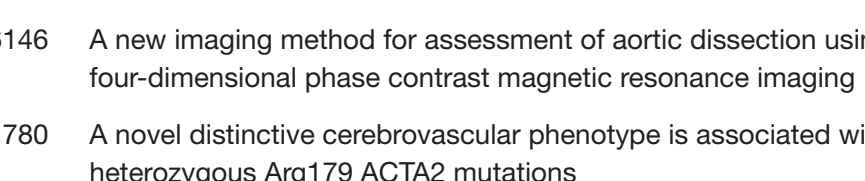

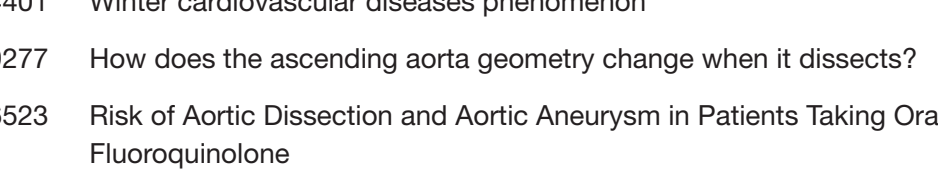

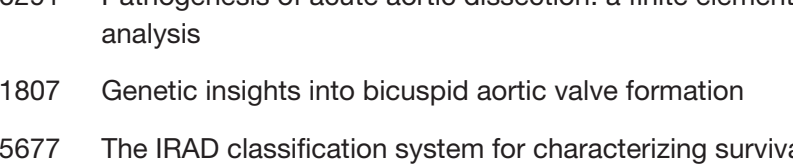

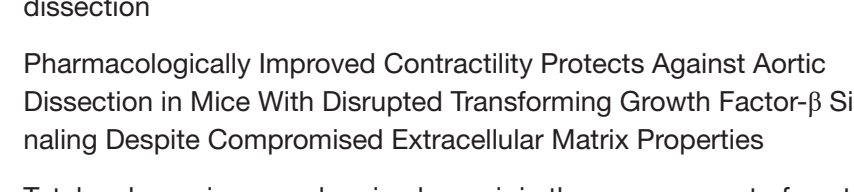

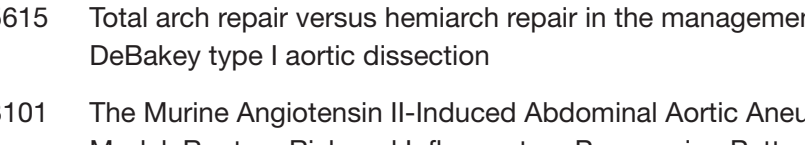

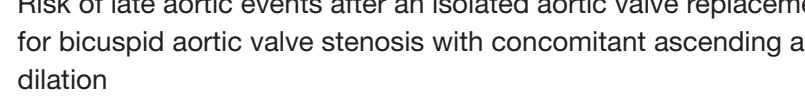

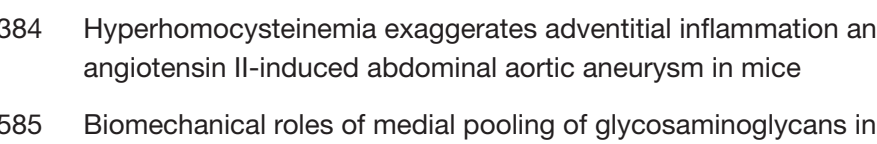

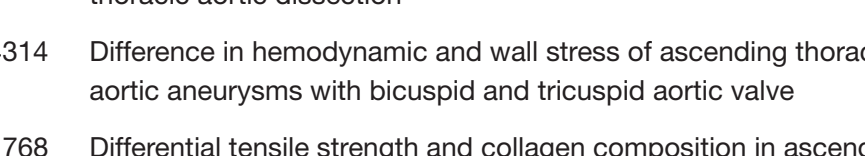

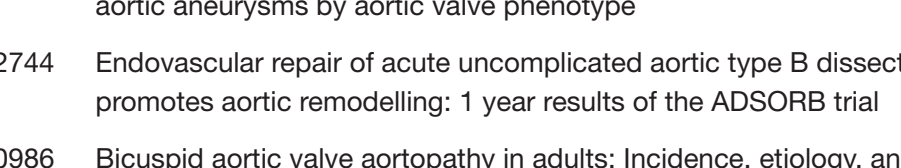

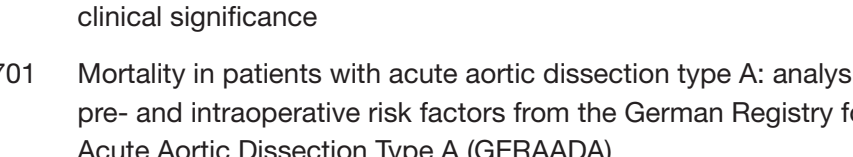

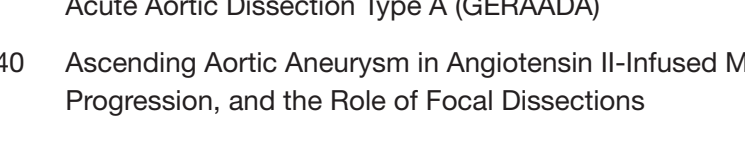

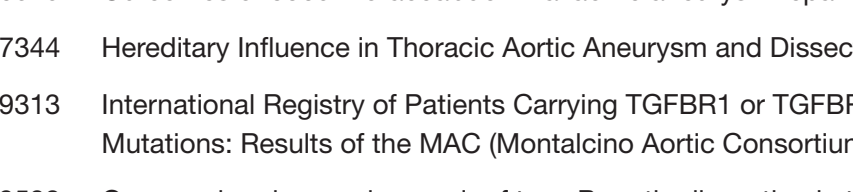

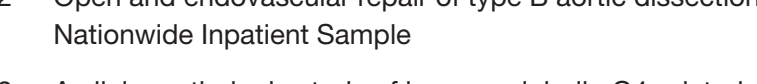

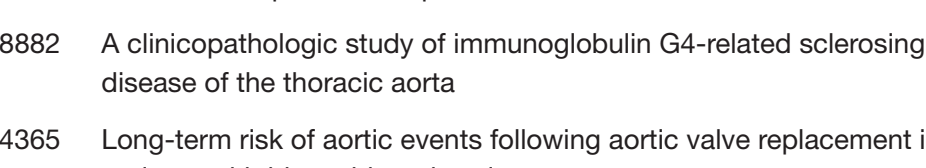

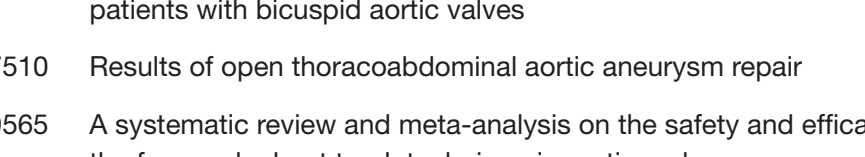

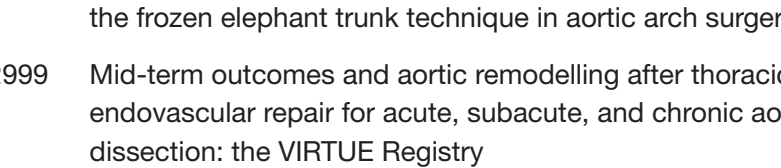

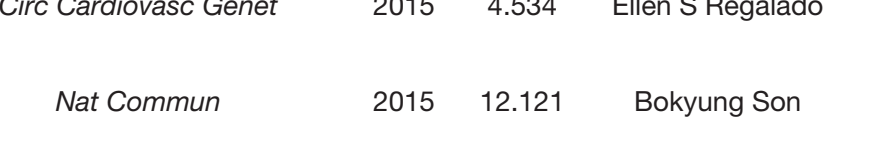

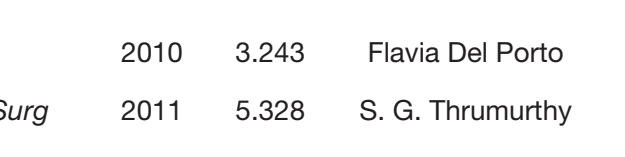

(n) surg

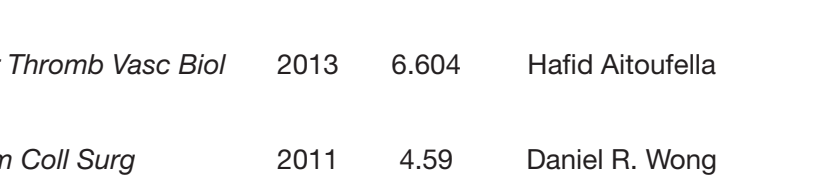

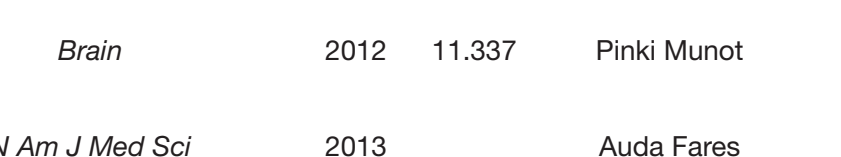

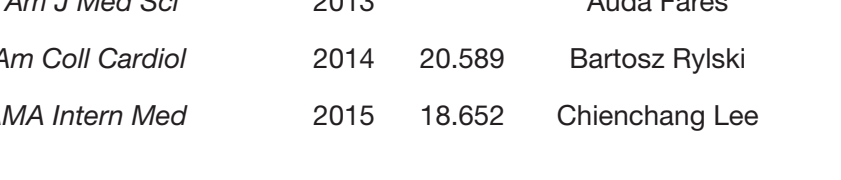

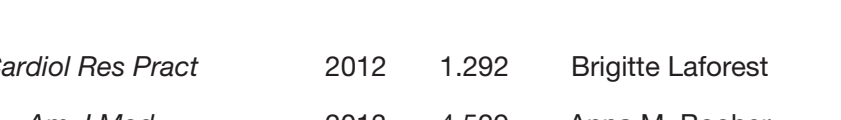

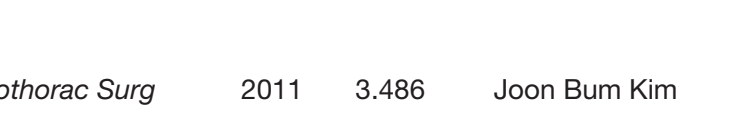

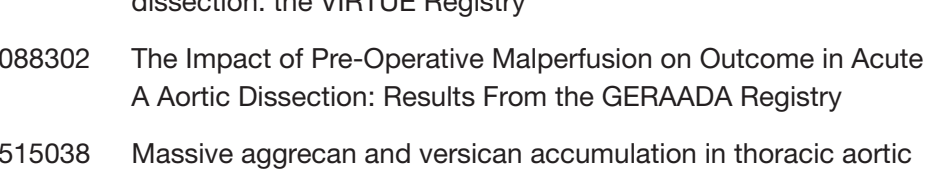

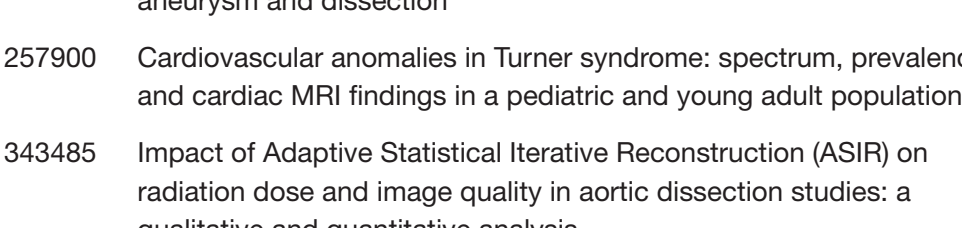

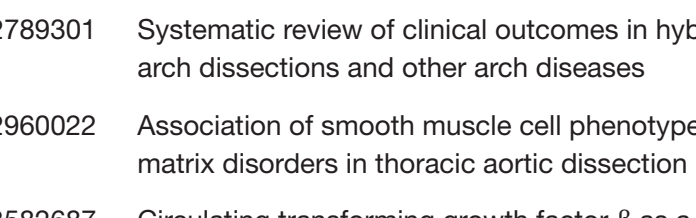

(neser

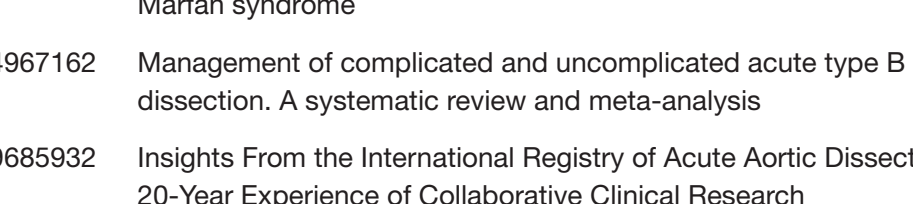




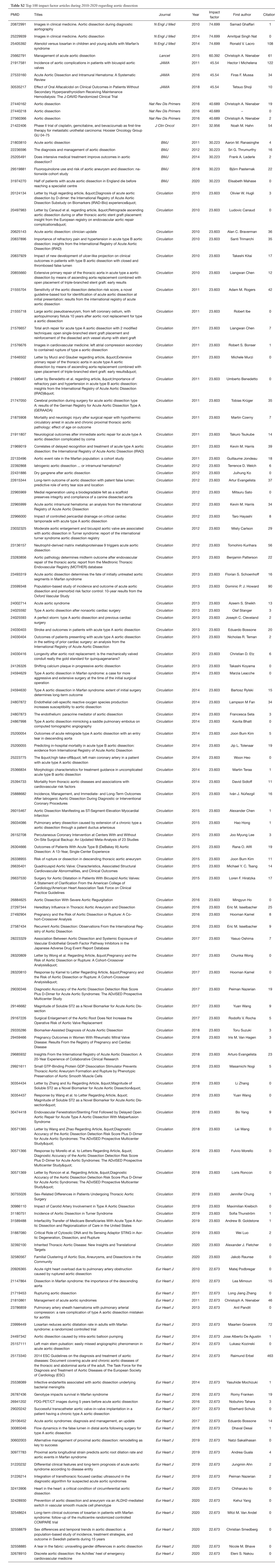

